\title{
PRODUÇÃO DE BIODIESEL A PARTIR DE ÓLEO RESIDUAL DE FRITURA: AVALIAÇÃO DAS CONDIÇÕES DE PRODUÇÃO VIA REAÇÃO DE TRANSESTERIFICAÇÃO
}

\author{
M. F. MARQUES ${ }^{1}$, P. S. MORAES ${ }^{1}$ e L. A. A. PINTO $^{1}$ \\ ${ }^{1}$ Universidade Federal do Rio Grande, Departamento de Química e Alimentos-EQA \\ mmsap1998@hotmail.com
}

\begin{abstract}
RESUMO - A queima de combustíveis fósseis ainda é a principal fonte de energia mundial. Substituir ou minimizar o uso desses recursos não renováveis consiste em uma crescente necessidade. Neste contexto, a produção de biodiesel utilizando como matéria-prima óleo residual, um poluente de solos e fontes de água, consiste em uma alternativa promissora. Pois, supriria a demanda energética, sem a produção de poluentes atmosféricos e ainda descartaria de forma adequada esse resíduo. O principal processo de produção de biodiesel, consiste basicamente na reação de transesterificação, na qual, um triglicerídeo presente no óleo reage com álcool primário, resultando em glicerina e biodiesel. Dessa forma, o presente trabalho teve como objetivo avaliar quatro parâmetros de processo: temperatura $\left({ }^{\circ} \mathrm{C}\right)$, tempo reacional, concentração do catalisador e a proporção de óleo e álcool, objetivando um maior rendimento em biodiesel. Foi utilizado como matéria-prima o óleo de soja residual oriundo da planta piloto BIOSUL, da Escola de Química e Alimentos da Universidade Federal do Rio Grande. Foi possível a produção de biodiesel com o uso dessa matéria-prima, sendo a melhor condição, com um rendimento de $71,77 \%$, quando a temperatura foi de $60{ }^{\circ} \mathrm{C}$, com $90 \mathrm{~min}$ de processo, adicionando $2 \%$ de catalisador $(\mathrm{KOH})$ e uma proporção de 1:12 de óleo e etanol.
\end{abstract}

\section{INTRODUÇÃO}

A exploração dos recursos naturais em particular os não renováveis, tendo como maior exemplo a produção de combustíveis à base de petróleo e seus derivados, vem cada vez mais despertando o interesse de empresários e pesquisadores na busca de alternativas, que amenizem seus custos e malefícios a natureza. Da mesma forma, diariamente pelos mais diversos setores produtivos são descartados inadequadamente inúmeros poluentes atmosféricos, aquáticos e terrestres agravando cada vez mais as condições ambientais do planeta. Neste contexto, utilizar um resíduo poluente do solo e lençóis freáticos como o óleo de fritura, para a obtenção de biodiesel, consiste em um alternativa altamente promissora.

A produção de biodiesel ocorre principalmente pelo processo de transesterificação. Os triglicerídios presentes no óleo reagem com álcool primário formando glicerina e biodiesel, pode-se utilizar catalisadores básicos ou ácidos, catálise heterogênea, enzimática entre outros. Vale salientar que a matéria-prima para produção deste biocombustível, consiste em um dos principais fatores para a otimização do processo de produção, porém a temperatura de reação, 
tipo de álcool, tempo reacional, tipo e concentração de catalisador, $\mathrm{pH}$, velocidade de agitação são fatores muito importantes, que ainda vem sendo estudados e avaliados, objetivando principalmente o rendimento em biodiesel (Haertel, 2009).

Neste sentido, utilizar como matéria-prima para a produção de biodiesel óleos vegetais não comestíveis, gorduras animais e óleos residuais vem cada vez mais se destacando pelo fato de representar cerca de $80 \%$ do custo de produção (Girish, 2013). Dessa forma o presente trabalho teve como objetivo avaliar quatro parâmetros de processo: temperatura $\left({ }^{\circ} \mathrm{C}\right)$, tempo reacional, concentração do catalisador e a proporção de óleo e álcool adicionado, tendo como resposta o rendimento em biodiesel, e assim determinar a melhor condição de produção.

\section{MATERIAIS E MÉTODOS}

\section{1. Óleo residual}

O óleo de soja residual utilizado foi coletado da planta piloto BIOSUL da Escola de Química e Alimentos - Campus Carreiros da Universidade Federal do Rio Grande (FURG). O óleo residual foi previamente decantado para retirada de sólidos grosseiros, após foi então homogeneizado e armazenado em um frasco âmbar.

\subsection{Análises físico-químicas}

Todas as análises físico-químicas foram determinadas pela metodologia oficial, descrita pelo Instituto Adolfo Lutz (Instituto Adolfo Lutz, 2008).

Índice de acidez (IA): Em um erlenmeyer de $125 \mathrm{~mL}$ foi adicionado $2 \mathrm{~g}$ de amostra (óleo residual). Após foi colocado $25 \mathrm{~mL}$ de solução éter etílico:álcool etílico na proporção de $2: 1(\mathrm{v} / \mathrm{v})$. O sistema foi agitado até a completa diluição do óleo. Foram adicionados 3 gotas do indicador fenolftaleína. E a titulação foi realizada com solução de $\mathrm{NaOH}(0,1 \mathrm{~N})$ até o surgimento da cor rosa, estável por 30 s. O cálculo foi realizado conforme Equação 1.

$$
I A=\frac{\left(V_{\mathrm{NaOH}} \times f \times 5,61\right)}{m_{\text {óleo inicial }}}
$$

onde: IA é o índice de acidez ( $\mathrm{mg} \mathrm{KOH} / \mathrm{g}$ ); $\mathrm{V}_{\mathrm{NaOH}}$ é o volume de titulante gasto $(\mathrm{mL})$; f é o fator de padronização do titulante (mol/L); 5,61 é o equivalente grama do $\mathrm{KOH}$; móleo inicial é a massa da amostra (g).

Umidade: Previamente um cadinho de alumínio foi levado a estufa por $1 \mathrm{~h}$ a $105^{\circ} \mathrm{C}$. Em seguida, colocou-se em dessecador por aproximadamente $15 \mathrm{~min}$ para o resfriamento total do mesmo. A massa do cadinho foi medida e foi adicionado 3,00 $\mathrm{g}$ da amostra. A amostra foi colocada em estufa a $105^{\circ} \mathrm{C}$. Após $1 \mathrm{~h}$ foi realizado a pesagem. Repetiu-se o procedimento até massa constante. Sendo calculada de acordo com a Equação 2.

$$
U=\frac{\left(m_{\mathrm{u} m i d a} \times m_{\text {seca }}\right)}{m_{\mathrm{u} \text { mida }}}
$$


onde: U é a umidade (\%); múmida é a massa inicial de óleo; mseca é a massa de óleo após período em estufa $(\mathrm{g})$.

Densidade: A determinação da densidade foi pela técnica de picnometria. Primeiramente, a massa do picnômetro limpo e vazio foi medida. O picnômetro foi preenchido com água para a calibração do mesmo. A temperatura medida no dia da análise foi de $27^{\circ} \mathrm{C}$ e a massa específica da água $\left(\mathrm{g} / \mathrm{cm}^{3}\right)$ tabelada correspondente foi de $0,99652 \mathrm{~g} / \mathrm{cm}^{3}$. De posse desses dados, foi possível obter a densidade da amostra de óleo residual na temperatura estabelecida, conforme Equação 3.

$$
\rho_{\text {oleo } H_{2} O}=\left(\frac{m_{\text {óleo }}}{m_{\text {ag }}}\right)
$$

\subsection{Reação de transesterificação}

Para a produção de biodiesel pela reação de transesterificação, primeiramente o catalisador básico hidróxido de potássio $(\mathrm{KOH})$ foi dissolvido em etanol, sob agitação magnética com controle da temperatura. Após completa dissolução e quando a temperatura reacional desejada foi atingida, adicionou-se a esta solução $50 \mathrm{~g}$ de óleo de fritura sob agitação magnética. Posteriormente foi deixado reagir até atingir o tempo reacional estudado. Em seguida, a solução foi colocada em um funil de separação para a decantação e visualização da separação de fases. A fase inferior (contendo sabão, glicerol e excesso de catalisador) foi retirada e reservada. A fase superior foi lavada com água destilada à temperatura ambiente até $\mathrm{pH}$ 7,0 e o excesso da mesma e de álcool foi retirado em estufa a vácuo, por $6 \mathrm{~h}$ à $60^{\circ} \mathrm{C}$.

\subsection{Análise estatística}

$\mathrm{Na}$ avaliação da melhor condição operacional para a produção de biodiesel, foi utilizado a comparação entre as médias com a realização do teste de Tukey, a um nível de confiança de 95\% ( $\mathrm{p}<0,05$ ), com o auxílio do software Statistic 8.0. Os valores dos parâmetros de estudo, apresentados na Tabela 1, foram estabelecidos através de dados da literatura e de testes preliminares.

Tabela 1 - Condições operacionais

\begin{tabular}{|c|c|c|}
\hline Parâmetros & \multicolumn{2}{|c|}{ Valor } \\
\hline$t(\min )$ & 30 & 90 \\
\hline $\mathrm{T}\left({ }^{\circ} \mathrm{C}\right)$ & 60 & 80 \\
\hline${ }^{*}[\mathrm{KOH}](\%)$ & 2 & 5 \\
\hline${ }^{* * *}$ (ól:et) & $1: 6$ & $1: 12$ \\
\hline
\end{tabular}

\section{RESULADOS E DISCUSSÃO}

\subsection{Análise físico-química do óleo residual}


Os testes de índice de acidez, umidade e massa específica da amostra de óleo residual e óleo de soja virgem estão descritos na Tabela 2. As análises foram realizadas em triplicata.

Tabela 2 - Parâmetros físico-químicos do óleo residual

\begin{tabular}{|c|c|c|c|}
\hline & $\begin{array}{l}\text { Índice de acidez } \\
\text { (mg KOH/g óleo) }\end{array}$ & $\begin{array}{l}\text { Umidade } \\
(\%)\end{array}$ & $\begin{array}{c}\text { Massa específica } \\
\left(\mathrm{g} / \mathrm{cm}^{3}\right)\end{array}$ \\
\hline Óleo residual & $1,08 \pm 0,02$ & $1,25 \pm 0,04$ & $0,919 \pm 0,003$ \\
\hline Óleo de soja virgem & $0,10 \pm 0,08$ & $0,05 \pm 0,05$ & $0,920 \pm 0,004$ \\
\hline
\end{tabular}

A determinação do índice de acidez apresenta a quantidade de ácido graxo livre (AGL) presente na amostra. Um elevado IA pode indicar que o óleo sofreu quebras em sua cadeia lipídica, proporcionando um maior teor de IA. Conforme Tabela 2, o IA do óleo residual utilizado foi superior quando comparado ao óleo de soja virgem, sugerindo que houve degradação térmica pelo processo de fritura. Segundo que pela resolução ANP 014/2012, o teor de IA presentes no óleo ou biodiesel, tem o limite máximo de 0,5 mg KOH/g óleo. Um elevado IA, juntamente com um alto teor de água proporciona menores rendimentos em biodiesel (Meier, 2014; Coutinho, 2015).

A determinação do percentual de umidade também consiste em um parâmetro de grande importância para um bom rendimento em biodiesel. Um elevado teor de água pode dificultar, ou até mesmo inviabilizar, o processo de produção de biodiesel via catálise alcalina, favorecendo a reação paralela, que consiste na reação de saponificação (Agaewal et al., 2012). Conforme pode ser observado na Tabela 2, o óleo residual apresentou um valor de umidade 25 vezes maior que a do óleo de soja virgem. Já os resultados de massa específica, não se alteraram com o processo de fritura, e encontraram-se de acordo com os parâmetros previstos pela ANVISA para óleos residuais.

\subsection{Análise estatística}

Mesmo utilizando valores já estabelecidos na literatura para os parâmetros em estudo (temperatura de processo, tempo reacional, concentração de catalisador e proporção de óleo e álcool), foram realizados testes preliminares. Pois devido ao uso de uma matéria-prima oriunda de um processo de fritura, ela poderia diferenciar-se tanto pelas condições desse processo (temperatura e tempo), assim como pelo alimento, a qual foi exposta.

Por meio dos testes preliminares foi observado que com uma concentração de $5 \%$ de catalisador juntamente a uma proporção de óleo e etanol de 1:6 (v/v), não ocorreu a separação de fases nos experimentos. $\mathrm{O}$ excesso de catalisador aliado a uma proporção relativamente baixa de etanol, favoreceu a reação inversa a transesterificação (formação de sabão). Consequentemente não houve separação de fases, independente da temperatura e do tempo reacional utilizados. Estes tratamentos foram descartados para a realização da análise estatística.

Foi realizado a comparação de médias pelo teste de Tukey ao nível de significância de $5 \%(\mathrm{p}<0,05)$. A Tabela 3 apresenta os tratamentos realizados e o respectivo percentual de rendimento em biodiesel obtido em cada um deles. 
Tabela 3 - Parâmetros de estudo e percentuais de Rendimento

\begin{tabular}{|c|c|c|c|c|c|}
\hline $\begin{array}{c}\text { Tratamento } \\
\left(\mathrm{n}^{\circ}\right)\end{array}$ & $\begin{array}{c}\text { Temperatura } \\
\left({ }^{\circ} \mathrm{C}\right)\end{array}$ & $\begin{array}{c}\text { Tempo } \\
(\mathrm{min})\end{array}$ & $\begin{array}{c}\text { Concentração de } \\
\text { KOH } \\
(\%)\end{array}$ & $\begin{array}{c}\text { Proporção óleo } \\
\text { etanol (v/v) }\end{array}$ & Rendimento (\%) \\
\hline \hline 1 & 80 & 90 & 2 & $1: 6$ & $55,96 \pm 0,9^{\mathrm{b}}$ \\
\hline 2 & 80 & 30 & 2 & $1: 6$ & $4,61 \pm 0,4^{\mathrm{g}}$ \\
\hline 3 & 60 & 90 & 2 & $1: 12$ & $71,77 \pm 0,8^{\mathrm{a}}$ \\
\hline 4 & 80 & 90 & 5 & $1: 12$ & $36,45 \pm 0,7^{\mathrm{e}}$ \\
\hline 5 & 60 & 30 & 5 & $1: 12$ & $26,57 \pm 0,4^{\mathrm{f}}$ \\
\hline 6 & 60 & 30 & 2 & $1: 6$ & $42,4 \pm 1,4^{\mathrm{c}}$ \\
\hline 7 & 80 & 30 & 2 & $1: 12$ & $9,85 \pm 0,2^{\mathrm{g}}$ \\
\hline 8 & 60 & 90 & 2 & $1: 6$ & $43,15 \pm 1,1^{\mathrm{cd}}$ \\
\hline 9 & 60 & 90 & 5 & $1: 12$ & $46,93 \pm 0,9^{\mathrm{d}}$ \\
\hline 10 & 80 & 30 & 5 & $1: 12$ & $13,9 \pm 0,9^{\mathrm{g}}$ \\
\hline
\end{tabular}

Letras diferentes em mesma coluna apresentam diferença significativa com $p<0,05$

Conforme pode ser observado na Tabela 3 , o tratamento $\mathrm{n}^{\circ} 8$ não diferiu significativamente do tratamento $\mathrm{n}^{\circ} 6$, tendo o tempo reacional como única condição distinta (valores de 90 min e 30 min respectivamente), estabelecendo que nessas condições o tempo não foi relevante no resultado final. Da mesma forma o tratamento $\mathrm{n}^{\circ} 8$ não diferiu do tratamento $\mathrm{n}^{\circ} 9$ com $5 \%$ de significância, porém nestas duas condições operacionais tanto a concentração de catalisador quanto a proporção óleo e etanol distinguem-se. Os tratamentos $\mathrm{n}^{\circ} 7$ e $\mathrm{n}^{\circ} 10$ também não apresentaram diferença entre as médias, apresentando apenas distintas concentrações de catalisador, propondo que nessas condições experimentais a concentração de catalisador não alterou o rendimento em biodiesel. Os demais experimentos apresentaram diferença com $95 \%$ de confiança.

Neste contexto, foi possível determinar que a melhor região de trabalho que proporcionou um maior rendimento em biodiesel, conforme os resultados apresentados na Tabela 3, foi na menor concentração de catalisador (2\%) e no maior tempo reacional (90 min), independente da temperatura e da proporção de óleo e etanol utilizado, conforme observado nos resultados dos tratamentos $\mathrm{n}^{\circ} 1$ e $\mathrm{n}^{\circ} 3$ com $55,96 \%$ e $71,77 \%$ de rendimento em biodiesel respectivamente.

\section{CONCLUSÃO}

Os resultados da análise físico-química para o óleo residual demonstraram que o óleo apresenta elevada acidez e umidade, sendo necessário um prétratamento para sua utilização na produção de um biodiesel de boa qualidade. O maior rendimento foi obtido nas seguintes condições: $60^{\circ} \mathrm{C}, 90$ min de processo, $2 \%$ de catalisador $(\mathrm{KOH})$ e uma proporção de 1:12 de óleo e etanol, obtendo-se $71,77 \%$ de rendimento em biodiesel.

\section{REFERÊNCIAS}

AGARWAL, M.; CHAUHAN, G.; CHAURASIA, S. P.; SINGH, K. Study of catalytic behaviour of $\mathrm{KOH}$ as homogeneous and heterogeneous catalyst for biodiesel production. J. Taiwan Inst. Chem. Eng. v. 43, p. 89-94, 2012. 
ANVISA. Óleos e gorduras usados em frituras. Disponível em: < /http://www.anvisa.gov.br/ALIMENTOS/informes/11_051004.htm>. Acesso em: 18 de março de 2017.

COUTINHO, V. V.; JESUS, T. M. de; FERNANDES, D. M.; MALPASS, G. R. P.; SILVA, P. P. Avaliação e aproveitamento do resíduo de óleo vegetal coletado no ru/uftm para a produção de biodiesel. In: Anais do XI Congresso Brasileiro de Engenharia Química em Iniciação Científica. São Paulo: Blucher, v. 1, p. 192-197, 2015.

GIRISH, N. Utilization of a cost effective solid catalyst derived from natural white bivalve clam shell for transesterification of waste frying oil. Fuel, v. 111, p. 653-658, 2013.

HAERTEL, P. L. Desenvolvimento de um novo processo para a produção de biodiesel etílico de mamona. (Dissertação de Mestrado em Química Tecnológica Ambiental), Universidade Federal do Rio Grande, RS, 2009.

INSTITUTO ADOLFO LUTZ. Métodos Fisico-Químicos para análises de alimentos. São Paulo: Instituto Adolfo Lutz, 2008.

MEIER T. R. W.; CRIPA F. B. C.; FEROLDI M.; PAULO CREMONEZ P.; SCHNEIDER L. T.; BONASSA G.; TELEKEN J. G. Avaliação da produção de ésteres metílicos e glicerol a partir das misturas de óleo residual, de soja e de canola. Rev. Tecnol., Maringá, p. 73-81, 2015. 